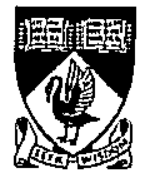

THE PERSISTENCE OF THE FEMALE WAGE DISADVANTAGE

by

Anh T. Le

and

Paul W. Miller

DISCUSSION PAPER 00.20

DEPARTMENT OF ECONOMICS

THE UNIVERSITY OF WESTERN AUSTRALIA

NEDLANDS, WESTERN AUSTRALIA 6907 
Anh T. Le

and

Paul W. Miller

Department of Economics, University of Western Australia, Nedlands, WA 6009

DISCUSSION PAPER 00.20

DEPARTMENT OF ECONOMICS

THE UNIVERSITY OF WESTERN AUSTRALIA

NEDLANDS, WESTERN AUSTRALIA 6907

*Financial assistance from the Australian Research Council is gratefully acknowledged. The views expressed in this paper are those of the authors and should not be attributed to the funding agency. Comments from Meng Xin, Alison Preston, David Johnson and two anonymous referees are acknowledged. 
THE PERSISTENCE OF THE FEMALE WAGE DISADVANTAGE

\begin{abstract}
Studies of the Australian labour market during the 1980s reported that the gender wage differential narrowed. However, a different story has emerged during the 1990s where the gender pay gap has persisted. A large part of the pay gap is attributable to different "treatments" of men and women in the labour market. This paper examines whether the female wage-disadvantaged state is a temporary or permanent phenomenon. The results show that while there is some mobility in the female wage distribution, there also exists a high degree of stickiness. It is argued that the wage-disadvantaged state for females is generally not a temporary phenomenon.
\end{abstract}

\title{
SUMMARY
}

This paper examines the persistence of the female wage disadvantage in the Australian labour market. The results suggest that for many females the wage-disadvantaged state is not temporary. 


\section{THE PERSISTENCE OF THE FEMALE WAGE DISADVANTAGE}

\section{INTRODUCTION}

A feature of the Australian labour market that continues to attract attention from academic researchers is the gender wage differential. Studies during the 1980s reported that the gender wage differential narrowed considerably. However, a different story has emerged during the 1990s where the gender pay gap has persisted. According to the Australian Bureau of Statistics' publication Employees Eamings and Hours, the hourly ordinary time wage differential between full-time adult non-managerial male and female employees was 9 percent in 1990, 6 percent in 1994 and 10 percent in 1998.

In the standard comparisons of male and female wages based on the Blinder (1973) decomposition, attempts are made to partition the difference in their earnings into two components. The first component is held to arise because females have fewer of the skills, such as formal education and job training, known to be associated with higher wages. For example, if women have, on average, one year of schooling less than men and each year of schooling is associated with 10 percent higher earnings, then women would be expected to have earnings 10 percent lower than men, ceteris paribus. Continuing with this example, as mean education levels do not change appreciably in the short term, this component of the gender wage differential would be expected to be reasonably stable from year to year. Indeed, Preston's (1997) study of the gender wage differential using 1981 and 1991 Census data reveals that the proportion of the gender wage gap due to this "skills" or "explained" component remained at around 28 percent over this ten-year period. ${ }^{1}$

The second component of the difference in the wages of males and females that is generally analysed is that due to different treatments in the labour market. For example, if men and women each have, on average, one year of training, but this training is associated with 15 percent higher earnings among men and only 5 percent higher earnings among women, then the mean earnings of women would be 10 percent lower than those of men. If this component of the gender wage difference is a reflection of labour market

\footnotetext{
${ }^{1}$ For summaries of studies of the Australian gender wage gap see Table 1 in Preston and Crockett (2000), Table 1 of Borland (1999) and Table 1 of Rummery (1992).
} 
processes, it would be expected to persist over time. In other words, if there is a wage differential between men and women, and this is linked to different treatments in the labour market, then these treatments would usually be expected to evolve slowly-the equal pay for equal work case of 1969 and the equal pay for work of equal value case in 1972 are exceptions to this. This description would be consistent with the "systematic unequal treatments" associated with the discrimination term commonly (though not necessarily correctly) applied to this part of the wage differential. ${ }^{2}$ Again, Preston's (1997) study can be used to illustrate this. There it is shown that when data from the 1981 and 1991 Censuses are analysed in similar ways, the "unexplained" or "unequal treatments" component of the gender wage gap has been fairly stable at around 72 percent over the ten-year period.

While there are alternative explanations of the gender wage differential, these are expected to be associated with stable labour market outcomes at the aggregate level. Consider, for example, some explanations that focus on the supply side. These show that equally qualified males and females may be paid different wages by a non-discriminating employer when geographical constraints characterise the job search process of married couples. Thus, during job search each spouse generates a range of wage offers in several different labour markets. It is unlikely that the best offers for both spouses will occur in the same location. When this occurs, one or both spouses must compromise and accept something less than the best offer. It is argued that it is generally the wife who makes the compromise, the result being that the wife receives a lower wage than her husband. Similarly, when married females move with their husbands the couple's primary objective is often to find the job that best matches the husband's qualifications. This tied-mover behaviour means that females have fewer opportunities to find jobs that match their skills [Frank (1978)]. Likewise, the gender wage differential might be associated with males having superior levels of productivity-related characteristics that are not measured in the data set analysed. Included might be characteristics like ambition and motivation. These factors would also be expected to be fairly stable from year to year.

\footnotetext{
${ }^{2}$ As labour market discrimination may be defined as systematic unequal treatment in terms and conditions of employment for groups of unequally productive workers, this "unequal treatments" component of the gender wage differential is often viewed as a measure of wage discrimination. Unequal treatments can involve a female treatment disadvantage and/or a male treatment advantage [see Cotton (1988)].
} 
Thus, the two components of the wage differential usually quantified in gender wage differential studies are both expected to be reasonably stable over short periods of time, and the available empirical evidence is consistent with this expectation. A somewhat sweeping summary of the Australian studies of the gender wage gap is as follows. Most studies report a difference in the mean hourly earnings of men and women of between 15 and 20 percent. When account is taken of the different skill levels of men and women, a gender wage differential of between 10 and 15 percent remains. The division of the wage differential between men and women into explained and unexplained components is reasonably robust across studies [e.g., Kidd and Shannon (1996), Kidd and Meng (1997), Meng (1999), Wooden (1999)], with around one-quarter being explained, and threequarters unexplained.

The decomposition outlined above deals with averages. When considering the individual, one needs to take into account the stochastic variation in earnings. Previous studies (e.g., Lillard and Willis (1978) for the US adult labour market, Miller (1989) for the Australian youth market) have shown that this is quite important. In other words, there is considerable change in an individual's relative position in the wage distribution between contiguous years. According to data from the Australian Bureau of Statistics' Survey of Employment and Unemployment Patterns, the simple correlation between the hourly wage rates in 1996 and 1997 is only 0.70 for males and 0.66 for females. This raises an interesting issue when considered in the context of the stability of the components of the aggregate-level gender wage differential: women as a group may have their skills undervalued in the labour market in contiguous years, but the particular women who fall into this category can vary from year to year.

This stochastic component to wages needs to be considered when drawing policy conclusions from the gender wage analyses conducted for the Australian labour market. Freebairn, Porter and Walsh (1987, pp.130-131) argue that for many individuals income disadvantage is a temporary rather than a lifetime phenomenon. Hence, in the context of the gender wage issue, a finding of considerable mobility in the wage distribution would require policy to be directed not at low-wage employment per se, but rather at the groups that have a high risk of being in relatively low-wage jobs on a permanent basis. Such groups would appear to fit the "discriminated against" definition. By way of comparison, a study of the youth labour market would also show that youth are concentrated in low- 
wage jobs. Yet youth move out of these jobs with time: low-wage employment for youth is largely a temporary phenomenon. The question of whether a similar situation prevails in the female labour market is addressed below.

In this paper the wage distributions of workers in 1996 and 1997 are examined. There are three main parts to the paper. First, wage regressions are computed for 1996 and 1997, and the gender wage differential in these years documented. Second, changes in the positions in the wage distributions held by both males and females in 1996 and 1997 are examined. Attempts are made to relate the findings from this analysis to the apparent stability of the "skills" and "unequal treatments" components of the gender wage differential in the Australian labour market. Third, the results are used to reflect on the meaning and determinants of "disadvantaged" status among females in the Australian labour market.

\section{THE GENDER WAGE GAP IN 1996 AND 1997}

To examine the gender wage gap in 1996 and 1997 wage equations are estimated using data from the ABS Survey of Employment and Unemployment Patterns (SEUP). The survey was conducted in three waves. Wave one covered the period from September 5 1994 to September 3 1995. The second wave covered the period from September 41995 to September 11996 and the third wave covered the period from September 21996 to August 311997 [ABS (1997)].

The SEUP contains data on three groups of individuals aged 15-59 at May 1995 who were residents of private dwellings. These groups consist of Jobseekers, Labour Market Program participants and a Population Reference group. ${ }^{3}$ Given the purpose of this study it is appropriate to focus on the Population Reference group. This is a random sample of the population. The initial data collection contained 2,311 persons [ABS (1997), Le and Miller (1998)].

There are a number of considerations regarding the data used in the analysis. First, the data file contains a complete work history for each individual over the sample period. For

\footnotetext{
${ }^{3}$ The Jobseeker group has been used by Le and Miller (2000) and the sample of Labour Market Program participants by Stromback, Dockery and Ying (1999).
} 
the analyses presented below, a snapshot of jobs at the time the income data were collected is needed. We therefore select for analysis the job the person held at the beginning of September in 1996 and 1997. Second, some individuals are recorded with more than one job. To ensure that each person is represented in the sample only once, the job that started closest to the date of data collection in each year is selected. Third, the sample is restricted to members of the Population Reference group who have completed full-time study at the time of the survey date and who have relevant earnings data in both 1996 and $1997 .{ }^{4}$ In other words, a balanced panel is being used.

The final consideration when using the SEUP is sample attrition. The wave one-wave two and the wave two-wave three attrition rates are 8.9 percent and 6.5 percent, respectively. A higher than average attrition rate is observed among males, young people and people who are renting accommodation. If attrition is based on unobservables then, unless an appropriate instrument is found, little can be done to adjust for the problem [see Fitzgerald, Gottschalk and Moffitt (1998)]. If attrition is based on observables then the bias can be adjusted using weights. In this paper, all analyses are weighted to reflect the population count at the initial point of recruitment and thus compensate for non-responses over time. Tests of statistical significance reported are based on weights scaled down to reflect the actual sample size rather than the population size.

Table 1 contains the means and standard deviations of the variables used in the analysis of earnings. ${ }^{5}$ The data in the table show that there is a 5 percentage points change in the average hourly wage between 1996 and 1997 . The gender wage gap was 18 percentage points in 1996 and 19 percentage points in 1997.

\footnotetext{
${ }^{4}$ We do not use the 1995 data as the income data were collected in two different time periods. For individuals who had the same job in May 1995 and September 1995, the data were collected in May 1995. For all others the data were collected in September 1995. While it is possible to make adjustments to the May data for average wage movements to September, this is not a good research strategy for a research project where the focus is on wage mobility across a short period of time.

${ }^{5}$ The data are for individuals working in both 1996 and 1997. For the larger sample working in 1996, and that of individuals working in 1997, the mean logarithmic earnings in each year are 2.67 and 2.73 respectively. There are only minor differences in observed characteristics between the subset of individuals working in both 1996 and 1997 and the slightly larger samples of individuals working in either year. Earnings regressions were estimated for individuals who worked in 1996 only and those who worked in both 1996 and 1997. The results were very similar across the two samples. Where unobserved factors are important the methods developed by Heckman (1979) for sample selection bias could be used. Correction for this type of bias using the Heckman procedure would need to rely on identification achieved through functional form rather than through exclusion restrictions in the current analysis. This basis for econometric identification has proven to be quite problematic in the past and is not attempted here.
} 
Most individuals are relatively well endowed with regard to educational attainment and labour market experience. For example, 19 percent of individuals have a bachelor degree or higher and a further 20 percent have a skilled vocational qualification. However, it should be noted that there is also a relatively high representation of individuals (31 percent) who have not completed high school. A comparison between males and females shows that differences in educational attainment are most striking for vocational qualifications and lower levels of educational attainment. For example, 28 percent of males possess a skilled vocational qualification compared to 11 percent of females. However, there are fewer males ( 2 percent) with a basic vocational qualification compared to females (10 percent). The percentage of males who have not completed high school (26 percent) is considerably lower than that of females (36 percent). Differences in educational attainment between males and females are consistent for both 1996 and 1997.

The typical worker has obtained, on average, 17 years of general labour market experience and 6 years of firm-specific experience. Again, a comparison between males and females shows that males have obtained, on average, 5 and 3 more years of on-thejob experience and firm-specific experience, respectively, than females. It is to be noted that the general labour market experience variable is obtained from a survey question on the individual's labour market involvement since leaving school. This measure therefore accounts for the total impact of career interruptions, though not the timing of such interruptions. Given the control for career interruptions, indirect controls such as that provided by the number of children are not used in the estimating equations. ${ }^{6}$

The typical worker is also likely to be married and reside in a capital city. Around onequarter of the individuals are employed in the public sector. There are also high representations of workers who are employed in firms with a very small number of employees (29 percent) as well as in firms with very large number of employees (32 percent). The differences between males and females with regard to these characteristics are relatively small.

\footnotetext{
${ }^{6}$ Experiments show that the age of children does not significantly affect the earnings of females. This suggests that these family variables proxy career interruptions.
} 
Table 1

Means and Standard Deviations of Variables, Population Reference Group

\begin{tabular}{|c|c|c|c|c|}
\hline & \multicolumn{2}{|c|}{1996} & \multicolumn{2}{|c|}{1997} \\
\hline Variable & Mean & Std. Dev & Mean & Std. Dev \\
\hline Log hourly wage-Total (\$) & 2.69 & 0.48 & 2.74 & 0.48 \\
\hline Log hourly wage-Males (\$) & 2.77 & 0.47 & 2.83 & 0.46 \\
\hline Log hourly wage-Females (\$) & 2.59 & 0.47 & 2.64 & 0.49 \\
\hline \multicolumn{5}{|l|}{ Educational attainment } \\
\hline Bachelor degree or higher (\%) & 17.5 & 38.0 & 18.8 & 39.1 \\
\hline Undergraduate or associate diploma (\%) & 9.5 & 29.4 & 9.9 & 29.8 \\
\hline Skilled vocational qualification (\%) & 19.8 & 39.9 & 20.0 & 40.0 \\
\hline Basic vocational qualification (\%) & 5.4 & 22.7 & 5.5 & 22.8 \\
\hline Attended highest level of secondary school (\%) & 17.2 & 37.8 & 15.6 & 36.3 \\
\hline Left school aged 16 years and over (\%) & 17.6 & 38.1 & 17.4 & 38.0 \\
\hline Left school aged 15 years and under (\%) & 12.9 & 33.5 & 12.8 & 33.4 \\
\hline \multicolumn{5}{|l|}{ General labour market experience } \\
\hline Experience (years) & 15.8 & 10.9 & 16.7 & 10.9 \\
\hline Duration of current job (years) & 5.8 & 7.1 & 6.1 & 7.1 \\
\hline \multicolumn{5}{|l|}{ English proficiency } \\
\hline Speaks English very well/well (\%) & 12.9 & 33.6 & 13.4 & 34.1 \\
\hline Speaks English fairly well/not well/not at all (\%) & 2.4 & 15.3 & 1.9 & 13.7 \\
\hline \multicolumn{5}{|l|}{ Marital status } \\
\hline Separated/divorced/widowed (\%) & 8.7 & 28.2 & 9.7 & 29.6 \\
\hline Never married (\%) & 26.3 & 44.0 & 25.0 & 43.3 \\
\hline Married (\%) & 65.0 & 47.7 & 65.3 & 47.6 \\
\hline Female (\%) & 46.6 & 49.9 & 46.6 & 49.9 \\
\hline Disability (\%) & 19.7 & 39.8 & 20.4 & 40.3 \\
\hline \multicolumn{5}{|l|}{ Birthplace } \\
\hline Born in main English-speaking country (\%) & 12.9 & 33.5 & 12.9 & 33.5 \\
\hline Born in other country (\%) & 10.4 & 30.5 & 10.4 & 30.5 \\
\hline Period of residence (years) & 5.1 & 10.8 & 5.3 & 11.2 \\
\hline \multicolumn{5}{|l|}{ Labour market history } \\
\hline Never worked (\%) & 2.7 & 16.1 & 2.7 & 16.1 \\
\hline $\begin{array}{l}\text { Looking for work since first left full-time } \\
\text { education (years) }\end{array}$ & 0.5 & 1.4 & 0.9 & 1.6 \\
\hline \multicolumn{5}{|l|}{ Area of residence } \\
\hline Major urban (\%) & 6.9 & 25.4 & 6.9 & 25.4 \\
\hline Other urban (\%) & 17.3 & 37.8 & 17.6 & 38.1 \\
\hline Rural (\%) & 16.7 & 37.3 & 16.4 & 37.1 \\
\hline Capital city (\%) & 59.2 & 49.2 & 59.1 & 49.2 \\
\hline Public sector (\%) & 24.7 & 43.2 & 24.7 & 43.2 \\
\hline Size of location 1-10 employees (\%) & 28.5 & 45.2 & 28.5 & 45.2 \\
\hline Size of location 11-50 employees (\%) & 26.3 & 44.0 & 26.3 & 44.0 \\
\hline Size of location 51-100 employees (\%) & 12.8 & 33.4 & 12.8 & 33.4 \\
\hline Size of location 100 employee or more (\%) & 32.4 & 46.8 & 32.4 & 46.8 \\
\hline Sample size & 1192 & & 1192 & \\
\hline Weighted estimate ('000) & 6618.3 & & 6618.3 & \\
\hline
\end{tabular}


While there have been improvements in the productivity-related characteristics (e.g., educational attainment, English proficiency) of individuals between 1996 and 1997, they have been relatively small. For example, the percentage of individuals with a bachelor degree or higher increased from 18 percent in 1996 to 19 percent in 1997 . Similarly, the percentage of individuals who speak a language other than English at home and who have a poor command of English declined only marginally between 1996 and 1997. More detailed study of the sample disaggregated by gender shows few gender differentials in this regard. The impacts of productivity-related characteristics and structural factors on earnings are examined below.

The earnings function is expressed as

$$
W_{i t}=\beta X_{i t}+\varepsilon_{i t}
$$

where, for individual $i$ in year $t, W$ is the natural logarithm of the hourly wage, $X$ is a vector containing the personal and job-related characteristics, $\beta$ is a set of weights to be estimated that link these characteristics to earnings, and $\varepsilon$ is a stochastic disturbance term. Estimates of $\beta$ will be obtained separately for 1996 and 1997 using Ordinary Least Squares.

In these estimations labour market experience is controlled for using measures of general labour market experience and job duration. Neither measure takes account of part-time work. This will be important where part-time work results in lower earnings growth than full-time work. Obtaining reliable estimates of this effect is made difficult by the fact that involvement in part-time work is not uniform across workers [see Rummery (1992) for discussion of the use of uniform adjustments to experience variables]. ${ }^{7}$ The available evidence [e.g., Jones and Long (1979)] suggests that each extra year of part-time work for a given amount of full-time work may reduce the wage by between 0.66 of one percent and 1 percent. Ignoring this effect, therefore, implies that our estimates will overstate the gender wage effect by 3 to 5 percent. $^{8}$ It should not have a major impact on the analysis of wage mobility among females that is the focus of the study.

\footnotetext{
${ }^{7}$ See Kidd and Shannon (1997) and Filer (1993) for discussion of the various alternatives for imputing work experience. One of the lessons from this research is that there is no single alternative to either the Mincer proxy or the measure of actual experience used in the current paper.

${ }^{8} 40$ percent of female workers and 7 percent of male workers are in part-time employment.
} 
A number of approaches may be taken to illustrate the relative pay positions of men and women in 1996 and 1997. In the current study, wage equations will be estimated for a pooled sample of men and women. The relative earnings disadvantage of women will be assessed through inclusion in the earnings equation of a dummy variable for gender. ${ }^{9}$

The Ordinary Least Squares results for earnings in 1996 and 1997 are presented in Table 2. As outlined previously, the models presented in this table have been estimated on data pooled across males and females. The results generally accord with a priori expectations and are consistent with previous studies. The F-statistics of 15.42 for the 1996 model and 12.43 for the 1997 model show that the variables included in these models are jointly significant in explaining variations in earnings. The adjusted $\mathrm{R}^{2}$ indicates that one quarter of the variation in the log of earnings is explained by the linear combination of variables listed in the right-hand side column of the table. While the adjusted $\mathrm{R}^{2}$ is consistent with models of this type, the results also indicate that unobservables play a large role in explaining variations in the log of earnings.

The Table 2 results show that educational attainment, general labour market experience, English proficiency, marital status, area of residence, the size of location of employment and gender significantly affect the earnings of individuals. For example, compared to individuals who left school before their $16^{\text {th }}$ birthday, those who possess a bachelor degree or higher earn at least 42 percent more. The earnings of individuals with vocational qualifications are at least 11 percent higher than that of early school leavers.

The relationship between labour market experience and earnings is non-linear. For example, evaluated at 10 years of labour market experience, for each extra year of experience the hourly wage increases by 1.0 percent, at 15 years it increases by 0.7 percent and at 28 years the hourly rate of pay starts to fall by a small amount with experience. In comparison, the relationship between firm-specific experience and earnings is dominated by the linear term. Furthermore, firm-specific skills have a smaller impact on earnings than general skills accumulated on-the-job.

\footnotetext{
${ }^{9}$ While this method has limitations such as constraining the estimates of the effects of schooling, labour market experience and other variables to be the same for both males and females, it offers an expedient way of summarising the data that is sufficient for the purpose of the current study. Miller's (1994) analysis of the Blinder decomposition shows that the simple dummy variable method yields findings the same as more complex methods for assessing the extent of gender wage discrimination.
} 
Table 2

Ordinary Least Squares Results of Earnings for the Population Reference Group

\begin{tabular}{|c|c|c|c|c|}
\hline & \multicolumn{2}{|c|}{1996} & \multicolumn{2}{|c|}{1997} \\
\hline Variable & Coefficient & t-ratio & Coefficient & t-ratio \\
\hline Intercept & 2.598 & 40.06 & 2.632 & 38.32 \\
\hline \multicolumn{5}{|l|}{ Educational attainment } \\
\hline Bachelor degree or higher & 0.443 & 7.86 & 0.419 & 7.26 \\
\hline Undergraduate or associate diploma & 0.265 & 5.38 & 0.173 & 3.36 \\
\hline Skilled vocational qualification & 0.130 & 3.08 & 0.106 & 2.33 \\
\hline Basic vocational qualification & 0.171 & 3.64 & 0.138 & 2.22 \\
\hline Attended highest level of secondary school & 0.138 & 2.81 & 0.181 & 3.48 \\
\hline Left school aged 16 years and over & 0.069 & 1.57 & 0.066 & 1.44 \\
\hline \multicolumn{5}{|l|}{ General labour market experience } \\
\hline Experience (years) & 0.016 & 3.54 & 0.021 & 4.58 \\
\hline Experience $/ 100$ & -0.029 & -2.78 & -0.041 & -3.77 \\
\hline Duration of current job (years) & 0.011 & 2.27 & 0.008 & 1.80 \\
\hline Duration of current job ${ }^{2} / 100$ & -0.017 & -1.07 & -0.015 & -1.00 \\
\hline \multicolumn{5}{|l|}{ English proficiency } \\
\hline Speaks English very well/well & -0.085 & -1.36 & 0.014 & 0.37 \\
\hline Speaks English fairly well/not well/not at all & -0.255 & -2.17 & -0.130 & -0.71 \\
\hline \multicolumn{5}{|l|}{ Marital status } \\
\hline Separated/divorced/widowed & -0.039 & -1.13 & -0.054 & -1.30 \\
\hline Never married & -0.144 & -4.27 & -0.101 & -3.06 \\
\hline Female & -0.140 & -4.99 & -0.157 & -5.49 \\
\hline Disability & -0.050 & -1.79 & 0.001 & 0.04 \\
\hline \multicolumn{5}{|l|}{ Birthplace } \\
\hline Born in main English-speaking country & -0.014 & -0.21 & -0.035 & -0.58 \\
\hline Born in other country & -0.069 & -0.85 & -0.178 & -2.60 \\
\hline Period of residence (years) & 0.003 & 1.05 & 0.003 & 1.45 \\
\hline \multicolumn{5}{|l|}{ Labour market history } \\
\hline Never worked & -0.023 & -0.49 & 0.053 & 0.69 \\
\hline $\begin{array}{l}\text { Looking for work since first left full-time } \\
\text { education (years) }\end{array}$ & -0.006 & -0.36 & -0.003 & -0.28 \\
\hline \multicolumn{5}{|l|}{ Area of residence } \\
\hline Major urban & -0.085 & -1.73 & -0.002 & -0.04 \\
\hline Other urban & -0.082 & -2.74 & -0.111 & -3.38 \\
\hline Rural & -0.072 & -2.20 & -0.081 & -2.19 \\
\hline Public sector & 0.021 & 0.77 & 0.002 & 0.06 \\
\hline Size of location 1-10 employees & -0.202 & -5.95 & -0.237 & -6.56 \\
\hline Size of location 11-50 employees & -0.152 & -5.05 & -0.147 & -4.97 \\
\hline Size of location 51-100 employees & -0.123 & -3.13 & -0.163 & -4.85 \\
\hline$F(28,1163)$ & 15.42 & & & \\
\hline$F(28,1163)$ & & & 12.43 & \\
\hline Adjusted $R^{2}$ & 0.25 & & 0.21 & \\
\hline Sample size & 1192 & & 1192 & \\
\hline Weighted estimates ('000) & 6618.3 & & 6618.3 & \\
\hline
\end{tabular}

Note: The t-ratios are formed using heteroscedasticity-consistent standard errors [see White (1980)].

With regard to structural influences, the results show that individuals living in capital cities receive significantly higher earnings than those living in other areas (e.g., other urban, rural). Furthermore, earnings vary directly with the size of location of 
employment. For example, compared to individuals who are working in a firm with 100 employees or more, those working in small firms (1-10 employees) earn at least 20 percent less and those working in medium-sized firms (11-50 employees) earn 15 percent less.

The Table 2 results also show that earnings are affected by gender, with the gender wage effect being around 15 percent. The size of the coefficient on gender in Table 2 is about one third of the size of the largest education variable (bachelor degree or higher). The result is consistent with previous Australian studies [see, for example, Miller (1994) where a similar methodology and specification of the estimating equation is employed]. While the results show that, compared to males, female workers earn 14 percent less in 1996 and 16 percent less in 1997, this difference between 1996 and 1997 is not statistically significant.

Hence, the conclusion that could be drawn from this study of wages is in line with previous research into gender wage effects in the Australian labour market. The average female worker is at a substantial wage disadvantage (around 19 percentage points in 1997), and very little of this wage disadvantage is due to the mean observed characteristics of female workers being different from the mean observed characteristics of male workers (the adjusted wage gap is 16 percentage points in 1997). The position of women in 1997 appears to be very much the same as it was in 1996. This finding is suggestive of a high degree of stability in the wage determination process in contiguous years. The study of wage mobility in the following section will assist in the interpretation of this wage disadvantage.

\section{WAGE MOBILITY ANALYSIS}

Table 3 presents information on the worker's position in the wage distribution in 1996 cross-classified by their position in the wage distribution in 1997. The top portion of this table is for females and the bottom portion is for males. The figures down the main diagonal represent individuals who maintained their position in the wage distribution over these years. Hence, of females in the bottom 20 percent of the wage distribution in 1996, 56 percent were also in the bottom 20 percent of the wage distribution in 1997 . At the top end of the wage distribution, 67 percent of females in the top wage bracket in 1996 were in the top wage bracket in 1997. 16 percent of this group, however, had moved back 
down to the $61-80$ percent range. The degree of stickiness at the upper and lower ends of the wage distribution is slightly higher for males than for females.

While there is a large degree of stickiness in the wage distribution, as illustrated by the relative magnitudes of the figures in the main diagonal, there is also quite considerable upward and downward mobility. For example, one-quarter of females in the bottom 20 percent of the wage distribution in 1996 had moved to the 21-40 percent range in 1997. One quarter of males in the 61-80 percent range in 1996 had dropped down to the 41-60 range in the following year. This suggests that the notion of disadvantage should be refined to take account of both the relative position in the wage distribution at a point in time and the length of time the individuals have been in that position.

Table 3

Mobility Patterns Between the Wage Distributions in 1996 and 1997

\begin{tabular}{|c|c|c|c|c|c|c|}
\hline \multicolumn{7}{|l|}{ FEMALES } \\
\hline \multirow[t]{2}{*}{ \% Distribution in 1996} & \multirow[b]{2}{*}{$0-20$} & \multirow[b]{2}{*}{$21-40$} & \multicolumn{3}{|c|}{ \% Distribution in 1997} & \multirow{2}{*}{$\begin{array}{r}\text { Total persons in each } \\
\text { quintile (a) }\end{array}$} \\
\hline & & & $41-60$ & $61-80$ & $81-100$ & \\
\hline $0-20$ & 55.7 & 25.2 & 8.4 & 5.3 & 5.3 & 131 \\
\hline $21-40$ & 13.5 & 47.8 & 27.0 & 9.0 & 2.7 & 111 \\
\hline $41-60$ & 12.3 & 17.5 & 44.7 & 19.3 & 6.1 & 114 \\
\hline $61-80$ & 5.8 & 8.3 & 14.2 & 53.3 & 18.3 & 120 \\
\hline $81-100$ & 5.0 & 5.8 & 6.7 & 15.8 & 66.7 & 120 \\
\hline \multicolumn{7}{|l|}{ MALES } \\
\hline \multirow[t]{2}{*}{ \% Distribution in 1996} & \multicolumn{5}{|c|}{ \% Distribution in 1997} & Total persons in each \\
\hline & $0-20$ & $21-40$ & $41-60$ & $61-80$ & $81-100$ & \\
\hline $0-20$ & 61.2 & 14.9 & 10.7 & 7.4 & 5.8 & 121 \\
\hline $21-40$ & 22.9 & 44.9 & 20.3 & 7.6 & 4.2 & 118 \\
\hline $41-60$ & 10.3 & 26.7 & 43.1 & 13.8 & 6.0 & 116 \\
\hline $61-80$ & 6.6 & 5.7 & 25.4 & 48.4 & 13.9 & 122 \\
\hline $81-100$ & 2.5 & 1.7 & 3.4 & 21.0 & 71.4 & 119 \\
\hline
\end{tabular}

This mobility could be due to changes in the skills of workers, or stochastic variation. To ascertain the extent to which the mobility is due to changes in the skills of workers, the following exercise was conducted.

First, an estimate of the wage structure was formed for males and females (separately) by pooling the data for 1996 and 1997 and estimating a human capital earnings function on 
this pooled data. This type of earnings function constrains the coefficients to be the same in each year of data collection, though the intercept term can change. ${ }^{10}$ Denote this set of estimates by $\hat{\beta}$. Then the characteristics of females $\left(X_{f}\right)$ are evaluated as follows ${ }^{11}$

$$
\begin{aligned}
& \hat{W}_{1996}=\hat{\beta}^{f} X_{1996}^{f} \\
& \hat{W}_{1997}=\hat{\beta}^{f} X_{1997}^{f} .
\end{aligned}
$$

Similar computations are undertaken for males. The predicted wages for 1996 and 1997 constructed in this manner are cross-tabulated in an analysis that parallels the data presented in Table 3. Table 4 lists relevant details.

\section{Table 4}

Mobility Patterns Between the Predicted Wage Distributions in 1996 and 1997

\begin{tabular}{|c|c|c|c|c|c|c|}
\hline \multirow[t]{2}{*}{ \% Distribution in 1996} & \multirow[b]{2}{*}{$0-20$} & \multirow[b]{2}{*}{$21-40$} & \multicolumn{3}{|c|}{ \% Distribution in 1997} & \multirow{2}{*}{$\begin{array}{r}\text { Total persons in each } \\
\text { quintile }\end{array}$} \\
\hline & & & $41-60$ & $61-80$ & $81-100$ & \\
\hline $0-20$ & 89.9 & 8.4 & 0.8 & 0.8 & 0.0 & 119 \\
\hline $21-40$ & 9.2 & 82.4 & 6.7 & 1.7 & 0.0 & 119 \\
\hline $41-60$ & 0.8 & 8.3 & 84.2 & 5.8 & 0.8 & 120 \\
\hline $61-80$ & 0.0 & 0.8 & 8.4 & 88.2 & 2.5 & 119 \\
\hline $81-100$ & 0.0 & 0.0 & 0.0 & 3.4 & 96.6 & 119 \\
\hline \multicolumn{7}{|l|}{ MALES } \\
\hline \multirow[t]{2}{*}{ \% Distribution in 1996} & \multicolumn{5}{|c|}{ \% Distribution in 1997} & Total persons in each \\
\hline & $0-20$ & $21-40$ & $41-60$ & $61-80$ & $81-100$ & \\
\hline $0-20$ & 94.1 & 5.0 & 0.0 & 0.8 & 0.0 & 119 \\
\hline $21-40$ & 5.9 & 86.6 & 7.6 & 0.0 & 0.0 & 119 \\
\hline $41-60$ & 0.0 & 7.5 & 85.0 & 6.7 & 0.8 & 120 \\
\hline $61-80$ & 0.0 & 0.0 & 7.6 & 86.6 & 5.9 & 119 \\
\hline $81-100$ & 0.0 & 0.8 & 0.0 & 5.9 & 93.3 & 119 \\
\hline
\end{tabular}

FEMALES

Several features of Table 4 can be observed. First, the figures in the leading diagonal indicate that there is a very high degree of stickiness in the wage distribution. For example, 90 percent of females predicted to be in the bottom 20 percent of the wage distribution in 1996 remain there in 1997. Similarly, 97 percent of female workers predicted to be in the 81-100 percent range of the wage distribution in 1996 are also in

\footnotetext{
${ }^{10}$ That is, a dummy variable for the 1997 observations is included in the pooled wage equation. This procedure should not be viewed as unnecessarily restrictive, as an F-test shows that it would even be valid to pool the data for 1996 and 1997 for the Table 2 results.

11 The data are pooled and one equation estimated in order to abstract from changes in estimated coefficients that may be a direct consequence of the considerable mobility in the wage distribution recorded in Table 3.
} 
the same part of the distribution in the following year. Second, there is little upward or downward mobility. For example, only 8 percent of females in the bottom 20 percent of the wage distribution in 1996 had moved to the $21-40$ percent distribution category in 1997. For the male sample, only 5 percent of male workers in the bottom 20 percent of the wage distribution in 1996 had moved to the 21-40 percent wage band by 1997 . 8 percent of females and males had dropped from the 41-60 percent range in 1996 to the 21-40 percent range in 1997. These findings suggest that changes in the skills and other characteristics of workers have a minimal impact on their mobility in the wage distribution between 1996 and 1997.

Hence, the analysis shows

1. The mean earnings of females were about 19 percent less than the mean earnings of males in both 1996 and 1997.

2. Very little of the gender pay gap can be accounted for by differences between males and females in the mean values of observed wage determinants.

3. There is considerable upward and downward mobility in the wage distribution between 1996 and 1997, for both males and females.

4. Almost all of this mobility seems to be due to stochastic variation in earnings. ${ }^{12}$

Are women who are classified as disadvantaged in the labour market in a given year similarly placed in the following year?

Given the findings reported above, the answer to this question could be No. It has been established that there is considerable mobility in the earnings distribution between contiguous years. Whether the earnings increment in a particular year is sufficient to overcome the initial earnings disadvantage needs to be assessed. The analyses reported below examine this.

Consider a female worker ( $i$ ) who is disadvantaged in the labour market in 1996. As defined in the wage discrimination literature, this would occur where the actual wage of

\footnotetext{
${ }^{12}$ Part of the stochastic variation may reflect differences in timing of wage adjustments under enterprise agreements. The data used do not permit this aspect to be examined.
} 
this female worker in year $t\left(W_{i f}^{f}\right)$ is less than one would forecast the woman to earn on the basis of her observable characteristics $\left(\hat{W}_{i f}^{f}\right)$.

There are various ways of generating these forecasts, including basing them on the male wage distribution or basing them on a weighted average of the male and female wage distributions. Consider the situation where the forecast is based on the male wage distribution. Then $\hat{W}_{i t}^{f}$ would be determined as

$$
\hat{W}_{i t}^{f}=\hat{\beta}^{m} X_{i t}^{f}
$$

where $\hat{\beta}^{m}$ is the set of coefficients estimated when the male data are pooled for 1996 and 1997 in a manner analogous to the exercise conducted using equations (2) and (3).

If $\hat{W}_{i t}^{f}>W_{i t}^{f}$ then the woman is categorised as disadvantaged in terms of wages.

A threshold of assessment could be built into this method of categorisation, so that only those women whose actual wages fall below the forecast wage by a given amount (say 10 percent) are categorised as disadvantaged. This threshold can obviously be varied to allocate any portion of female workers to the wage-disadvantaged category. For example, in 1996, 53 percent of female workers have a wage 10 percent or more below the forecast wage, and one-third of female workers have a wage 26 percent or more below the forecast wage. In 1997,55 percent of female workers have a wage 10 percent or more below the forecast wage and one-third of female workers have a wage 28 percent or more below the forecast wage.

Table 5 presents data on the associations between the predicted earnings of females in 1996 and 1997. The first panel of Table 5 presents information on whether female workers were disadvantaged in 1996 cross-classified by their status in this regard in 1997. In this instance "disadvantaged" is defined as having a wage 10 percent or more less than the predicted wage. The second panel presents information on whether female workers were disadvantaged in 1996 cross-classified by their disadvantaged status in 1997, with "disadvantaged" being defined in this instance as being in the one-third of workers with the largest discrepancy between actual and predicted wage. 
The data show that there are sizeable changes in the disadvantaged status of females over the two years period. According to the data in panel A of Table 5, 53 percent (i.e., 313 out of 596) of female workers were disadvantaged in the wage determination process in 1996. Of these, 81 percent experienced a similar outcome in 1997, but 20 percent exited this category over the same period. It can also be observed that 26 percent of females who were in the "not wage disadvantaged" category in 1996 experienced a fall in wages that resulted in them being classified as wage disadvantaged in the following year.

Turning to the data in panel B of Table 5, of the one-third of female workers who have a wage 26 percent below the predicted wage in 1996, 68 percent are similarly categorised as wage disadvantaged in the following year. However, there is also a sizeable representation of female workers (32 percent) who are categorised as at a wage disadvantage in 1996 who had moved out of this category in the following year. Similarly, 16 percent of the female sample who were not wage disadvantaged in 1996 were in the wage-disadvantaged category in 1997. Therefore, the data show that while there are improvements in the relative earnings of some females, there are many women who experienced deterioration in their relative wage position, so that they actually move into the wage-disadvantaged category.

Table 5

Cross-Tabulation of Percent of Females Whose Actual Wage is Below the Predicted Wage, 1996-1997

\begin{tabular}{|c|c|c|c|c|}
\hline \multicolumn{5}{|l|}{ Panel A } \\
\hline \multirow[b]{2}{*}{ Disadvantaged in 1996 (\%) (a) } & \multicolumn{2}{|c|}{ Disadvantaged in $1997(\%)$ (a) } & \multirow[t]{2}{*}{ Total } & \multirow[t]{2}{*}{ Number } \\
\hline & $\mathrm{NO}$ & $Y E S$ & & \\
\hline NO & 74.2 & 25.8 & 100.0 & 283 \\
\hline$Y E S$ & 19.5 & 80.5 & 100.0 & 313 \\
\hline Total & & & & 596 \\
\hline
\end{tabular}

\begin{tabular}{llrrr}
\hline Panel B & & & \\
\hline & & Disadvantaged in 1997 (\%) (b) & Total & Number \\
\cline { 2 - 3 } Disadvantaged in $1996(\%)$ (b) & NO & YES & & \\
NO & 34.0 & 16.0 & 100.0 & 399 \\
YES & 32.0 & 68.0 & 100.0 & 197 \\
Total & & & & 596 \\
\hline Note: & $\begin{array}{l}\text { (a) Disadvantage is defined in this panel as having an actual wage 10 percent or more below the } \\
\text { predicted wage. }\end{array}$ \\
(b) Disadvantage is defined in this panel as being among the one-third of workers with the largest \\
discrepancy between actual and predicted wages. In 1996 this refers to an actual wage 26 percent \\
or more below the predicted wage. In 1997 this refers to an actual wage 28 percent or more below \\
the predicted wage.
\end{tabular}


A major message from Table 5 is that a person's labour market history is a key factor in determining their current labour market outcome. A more formal summary of the linkages between being disadvantaged in the labour market in contiguous years can be provided through application of the bivariate probability model used by Miller (1989).

From equation (1), the probability that individual $i$ is disadvantaged in year $t$ is given by

$$
\begin{aligned}
& \operatorname{Pr}\left(\beta X_{i t}+\varepsilon_{i t}<W_{i t}^{*}\right) \\
& =\operatorname{Pr}\left(W_{i t}^{*}-\beta X_{i t}>\varepsilon_{i t}\right)
\end{aligned}
$$

where $W_{i t}^{*}$ is the (arbitrary) threshold used to define "wage disadvantaged". This model can be operationalised by defining the threshold value $\left(e . g ., W_{i t}^{*}=\hat{W}_{i t}^{f}-c\right.$, where $c$ might be a 10 percent margin) and constructing a binary index $\left(P_{i t}\right)$ for use in the bivariate probability model. Hence,

$$
\begin{aligned}
& \mathrm{P}_{\mathrm{it}}=1 \text { if } \mathrm{W}_{\mathrm{it}}<\mathrm{W}^{*} \text { it } \text {, or individual } i \text { is wage disadvantaged in year } t, \\
& \mathrm{P}_{\mathrm{it}}=0 \text { otherwise. }
\end{aligned}
$$

The joint probability of being wage disadvantaged in contiguous years, denoted $P_{i t, t+1}$, may be obtained by estimating the bivariate probit model represented by

$$
P_{i t, t+1}=F\left(\beta X_{i t}, \beta X_{i t+1}, \rho\right)
$$

where $F$ is the cumulative standard bivariate normal and $\rho$ denotes the correlation between the disturbances in adjacent years. Note that the coefficients in this model are constrained to be the same in each year, a procedure that is consistent with the constraint built into the predicted wage, $W_{i t}^{f}$.

The interpretation of $\rho$ can be aided by discussing the unobservables captured in the disturbance term of the equation for year $t$ in terms of "permanent" and "transitory" factors. If an influence is permanent, then it tends to result in a (say) positive residual in each year. $\rho$ will then be positive. If the unobservables are transitory, then the disturbance terms may not be correlated. Factors that might lead to a positive correlation between the disturbance terms in contiguous years include individual (e.g., motivation), institution (e.g., discrimination), and labour market (e.g., inertia models of labour market outcomes) factors. 
Table 6 presents the results from single equation and bivariate probit models of wage disadvantaged status for females where the dependent variable is the binary index $P_{i t}$ defined above. ${ }^{13}$ The single equation model predicts membership of the wagedisadvantaged category in a given year and is used as a benchmark set of results. In this estimation the coefficients in the model for 1996 are constrained to be the same as for 1997. This is the type of equation that a researcher having access only to cross-sectional data would estimate. While the McFadden $\mathrm{R}^{2}$ for the single equation and bivariate equation are standard for these models, it indicates that the unexplained component plays a large role in determining female wage disadvantage. Kuhn (1987) found that in addition to the standard measures of wage discrimination (e.g., human capital characteristics), other measures (e.g., differences in wage benefits, the type of treatment received on the job) not directly observable by researchers are important determinants of gender wage discrimination in the U.S. labour market.

With regard to observable measures, the Table 6 results show that the significant influences on the probability of females being categorised as disadvantaged at any point in time include educational attainment, English proficiency, marital status, disability status, the sector of employment and the size of the location of employment. For example, compared to female workers who left school before their $16^{\text {th }}$ birthday, those with higher levels of education are less likely to be categorised as being wage disadvantaged at any point in time. The result for limited English skills might seem perverse, but is readily explained. Limited English skills are associated with markedly lower (45 percent) wages in the male labour market, which provides the benchmark for the assessment of disadvantaged status. However, in the female labour market, limited English skills do not significantly reduce earnings. Hence, females having this characteristic will appear not to be wage disadvantaged compared to those who speak English only. A similar interpretation can be attached to the disability variable.

\footnotetext{
${ }^{13}$ It is noted that in this sample, it turns out that exactly one-half the workers are females. Hence, the sample size for the estimates for females in Table 6 is one-half that for the pooled sample in Table 1.
} 
Table 6

Bivariate Probit Estimation of Wage-Disadvantaged Model for Females

\begin{tabular}{|c|c|c|c|c|}
\hline & \multicolumn{2}{|c|}{ Single equation (a) } & \multicolumn{2}{|c|}{ Bivariate (a) } \\
\hline Variable & Coefficient & t-ratio & Coefficient & t-ratio \\
\hline Intercept & 1.037 & 3.61 & 0.876 & 3.49 \\
\hline \multicolumn{5}{|l|}{ Educational attainment } \\
\hline Bachelor degree or higher & -0.422 & -1.92 & -0.494 & -2.70 \\
\hline Undergraduate or associate diploma & -0.812 & -3.43 & -0.716 & -3.73 \\
\hline Skilled vocational qualification & -0.424 & -1.83 & -0.344 & -1.76 \\
\hline Basic vocational qualification & -0.587 & -2.44 & -0.625 & -3.08 \\
\hline Attended highest level of secondary school & -0.426 & -1.94 & -0.320 & -1.71 \\
\hline Left school aged 16 years and over & -0.539 & -2.67 & -0.455 & -2.66 \\
\hline \multicolumn{5}{|l|}{ General labour market experience } \\
\hline Experience (years) & 0.027 & 1.21 & 0.028 & 1.44 \\
\hline Experience $/ 100$ & -0.034 & -0.56 & -0.040 & -0.80 \\
\hline Duration of current job (years) & -0.048 & -1.64 & -0.028 & -1.16 \\
\hline Duration of current job ${ }^{2} / 100$ & 0.208 & 1.47 & 0.082 & 0.73 \\
\hline \multicolumn{5}{|l|}{ English proficiency } \\
\hline Speaks English very well/well & -0.210 & -0.81 & -0.145 & -0.66 \\
\hline Speaks English fairly well/not well/not at all & -1.389 & -2.41 & -1.679 & -2.96 \\
\hline \multicolumn{5}{|l|}{ Marital status } \\
\hline Separated/divorced/widowed & -0.652 & -3.61 & -0.487 & -3.15 \\
\hline Never married & -0.047 & -0.32 & 0.041 & 0.32 \\
\hline Disability & -0.331 & -2.26 & -0.408 & -3.12 \\
\hline \multicolumn{5}{|l|}{ Birthplace } \\
\hline Born in main English-speaking country & 0.077 & 0.26 & 0.285 & 1.24 \\
\hline Born in other country & 0.346 & 0.89 & 0.309 & 0.98 \\
\hline Period of residence (years) & 0.008 & 0.74 & -0.00007 & -0.01 \\
\hline \multicolumn{5}{|l|}{ Labour market history } \\
\hline Never worked & 0.453 & 1.21 & 0.377 & 1.02 \\
\hline $\begin{array}{l}\text { Looking for work since first left full-time } \\
\text { education (years) }\end{array}$ & -0.051 & -1.20 & -0.027 & -0.79 \\
\hline \multicolumn{5}{|l|}{ Area of residence } \\
\hline Major urban & 0.156 & 0.70 & 0.113 & 0.64 \\
\hline Other urban & 0.071 & 0.43 & 0.039 & 0.26 \\
\hline Rural & 0.300 & 1.92 & 0.344 & 2.56 \\
\hline Public sector & -0.564 & -4.00 & -0.462 & -3.91 \\
\hline Size of location 1-10 employees & -1.052 & -6.75 & -0.953 & -7.31 \\
\hline Size of location 11-50 employees & -0.455 & -3.01 & -0.387 & -3.04 \\
\hline Size of location 51-100 employees & -0.282 & -1.43 & -0.239 & -1.40 \\
\hline$x^{3}(27)$ & 218.92 & .. & .. & - \\
\hline McFadden $R^{2}(\mathrm{~b})$ & 0.13 & .. & 0.16 & \\
\hline$\rho$ &.. & .. & 0.575 & 10.87 \\
\hline Sample size & 596 & & 596 & \\
\hline Weighted estimates ('000) & 3084.4 & & 3084.4 & \\
\hline
\end{tabular}

Note: (a) The coefficients in this column are constrained to be the same in 1996 and 1997.

(b) The McFadden $R^{2}$ is calculated as $1-\left(1_{m} l_{0}\right)$, where $1_{m}=$ the maximised log-likelihood value of the model and $1_{0}=$ the $\log$-likelihood value if he non-intercept coefficients are restricted to zero [see Veall and Zimmermann (1996)].

The results from the bivariate probit wage disadvantaged model for females show the correlation between the residuals in adjacent years $(\rho)$ is positive, and highly significant 
(' $t$ ' of 10.87). This indicates that female workers in the wage-disadvantaged category in 1996 are likely to be similarly placed in the following year. In other words, the unobservables captured in the disturbance term have a substantial permanent component.

Similar to the results from the single equation model, educational attainment has significant, negative influences on the probability of female workers being categorised as wage disadvantaged in 1996 and 1997. In this case, the crucial distinction is again between individuals who left school before their $16^{\text {th }}$ birthday and the other educational categories.

In addition to human capital characteristics, female workers who are separated, divorced or widowed are less likely to experience wage disadvantage in 1996 and 1997 than those who are married. Moreover, females who reside in rural areas have a higher probability of being in the wage-disadvantaged category in both years compared to those living in capital cities.

The sector of employment and the size of the location of the firm are also important determinants of the probability of being wage disadvantaged in contiguous years. Thus, compared to female workers employed in the private sector, those working in the public sector have a lower probability of being in the wage-disadvantaged category. It can also be observed that women working in very large firms (i.e., 100 employees or more) are more likely to experience wage disadvantage than those working in smaller firms.

In order to understand a little more of what these results mean, predicted probabilities of being wage disadvantaged, as defined here, in 1996, in 1997, and in both 1996 and 1997 are computed. These will be calculated for a hypothetical female worker having the mean characteristics of the sample. ${ }^{14}$ The results from the single equation probit model show that the probability of being wage disadvantaged in 1996 or 1997 for this "representative" female is 53 percent. Where the probabilities of being in the wage-disadvantage state in 1996 and 1997 are independent, the joint probability of being wage disadvantaged in both

\footnotetext{
${ }^{14}$ There are various methods commonly adopted for computing predictions of this type. These include the method adopted here of using the mean of variables other than those represented in each part of Table 7, and using some coefficients only (e.g., private sector workers, major urban areas). In the current analysis this choice alters the predictions for all groups in each comparison in a reasonably uniform manner and so is not of any real consequence.
} 
1996 and 1997 is the product of the two marginal probabilities for the two years, namely 0.28. However, the estimates from the bivariate probability model show a significant positive correlation of the disturbance terms in the models of wage disadvantage in 1996 and 1997. Consequently, the joint probability of being in the wage-disadvantaged state will exceed the product of the marginal probabilities. The estimate of the joint probability of being in the wage-disadvantaged state in 1996 and 1997 is given as $F\left(X_{i t} \hat{\beta}, X_{i t+1} \hat{\beta}, \hat{\rho}\right)$, where $F$ is the bivariate standard normal cumulative density function. The estimate of the joint probability is 0.38 , which is considerably more than the estimate obtained under the independence assumption. ${ }^{15}$

The joint probability of being categorised as wage disadvantaged in 1996 and escaping from this state by 1997 can be computed as $F\left(X_{i t} \hat{\beta},-X_{i t+1} \hat{\beta},-\hat{\rho}\right)$. For the hypothetical worker referenced above, this probability is 0.15 . As around 53 percent of workers are wage disadvantaged, this means that 28 percent of those who are wage disadvantaged in a particular year are likely to escape this status within twelve months. ${ }^{16}$

It is difficult to say whether a 28 percent conditional exit rate over a twelve month period is large or small: there is an absence of a comparison literature. Lillard and Willis' (1978) study of males in the U.S. may provide some insights. They show that of those individuals below the poverty line in a given year, 55 percent of whites and 35 percent of blacks were out of poverty in the following year. Given this, the 28 percent exit rate in the current analysis may seem low. However, the Lillard and Willis' (1978) study was for males, and given the degree of occupational segregation on the basis of gender, this is less than ideal as a yardstick. ${ }^{17}$ Given this situation, differences across groups might be used as a way of accumulating some information in this regard. Hence, various probabilities are computed for two groups of variables, educational attainment and size of location of employment. These are presented in Table 7.

\footnotetext{
${ }^{15}$ Informed statements on the size of this probability are impeded by the absence of a comparison literature in Australia. The study of the U.S. labour market by Lillard and Willis (1978) shows that 15 percent of whites and 35 percent of blacks were in poverty in each of the three years reviewed.

${ }^{16}$ Hence 72 percent of those classified as wage disadvantaged in one year would be in the same state in the following year. By comparison, of those not in the wage disadvantaged state in the current year, only 32 percent will be in the wage disadvantaged state in the following year. As with the Table 5 data, a person's labour market history is important to their current labour market outcome.

${ }^{17}$ Though it is to be noted that the degree of male wage mobility in the SEUP data appears to be less than for females.
} 
Table 7

Predicted Probabilities of being Wage Disadvantaged

\begin{tabular}{|c|c|c|c|c|}
\hline Category & $\begin{array}{r}\text { Marginal } \\
\text { probability }\end{array}$ & $\begin{array}{r}\text { Joint } \\
\text { probability } \\
\text { of same state }\end{array}$ & $\begin{array}{r}\text { Joint } \\
\text { probability } \\
\text { of different } \\
\text { states }\end{array}$ & $\begin{array}{r}\text { Conditional } \\
\text { probability } \\
\text { of exit }\end{array}$ \\
\hline Educational attainment & (i) & (ii) & (iii) & (iv) \\
\hline Bachelor degree or higher & 0.529 & 0.338 & 0.153 & 0.312 \\
\hline Undergraduate or associate diploma & 0.376 & 0.255 & 0.148 & 0.367 \\
\hline Skilled vocational qualification & 0.528 & 0.399 & 0.151 & 0.275 \\
\hline Basic vocational qualification & 0.463 & 0.288 & 0.151 & 0.344 \\
\hline $\begin{array}{l}\text { Attended highest level of secondary } \\
\text { school }\end{array}$ & 0.529 & 0.409 & 0.151 & 0.270 \\
\hline Left school aged 16 years and over & 0.483 & 0.353 & 0.153 & 0.302 \\
\hline Left school aged 15 years and under & 0.690 & 0.545 & 0.136 & 0.200 \\
\hline Size of location & & & & \\
\hline $1-10$ employees & 0.300 & 0.184 & 0.136 & 0.425 \\
\hline $11-50$ employees & 0.529 & 0.387 & 0.152 & 0.282 \\
\hline 51-100 employees & 0.597 & 0.449 & 0.148 & 0.248 \\
\hline 100 employees or more & 0.701 & 0.551 & 0.135 & 0.197 \\
\hline
\end{tabular}

Note: (i) Calculated as $\Phi\left(X_{i t} \hat{\beta}\right)$ from the single equation probit estimates in Table 6.

(ii) Calculated as $F\left(X_{i l} \hat{\beta}, X_{i t+1} \hat{\beta}, \hat{\rho}\right)$ from the bivariate probit estimates in Table 6.

(iii) Calculated as $F\left(X_{i t} \hat{\beta},-X_{t+1} \hat{\beta},-\hat{\rho}\right)$ from the bivariate probit estimates in Table 6.

(iv) Calculated as (iii)/[(ii) + (iii)].

With regard to educational attainment, several features can be observed. First, compared to females who had left school before their $16^{\text {th }}$ birthday, those in other educational categories have a lower probability of being categorised as at a wage disadvantage in either year [column (i)]. For example, the probabilities of being in the wagedisadvantaged category in 1996 or 1997 for females with a bachelor degree or higher, those with a diploma and those who had left school at aged 15 years and under are 53 percent, 38 percent and 69 percent, respectively.

Second, females in the benchmark group of having left school before their $16^{\text {th }}$ birthday have a higher joint probability of being wage disadvantaged in contiguous years [55 percent, see column (ii)]. Among females with a bachelor degree or higher, a diploma, or a basic vocational qualification, the probabilities of being categorised as at a wage disadvantage in both 1996 and 1997 are 34 percent, 26 percent and 29 percent, respectively.

Third, females who had left school aged 16 years and over and those with higher levels of educational attainment have a slightly higher joint probability of being categorised as wage disadvantaged in 1996 and yet not being in this state the following year than those 
from the benchmark group. Thus, females from the benchmark group are predicted to have a 14 percent chance of being in these different wage comparison categories in 1996 and 1997 compared to 15 percent for females in the other educational categories [column (iii)].

Fourth, the conditional probability of exit [column (iv)] shows that females who left school before their $16^{\text {th }}$ birthday have a lower probability of exiting the wagedisadvantaged state than those with higher levels of education. For example, the conditional probability of leaving the wage-disadvantaged state is 20 percent for females with a low level of schooling compared to 31 percent for those with a bachelor degree or higher. These results suggest that while the wage-disadvantaged state is not a permanent one for females, it is more difficult for those with low levels of education to depart this state than those with higher educational attainment. At this stage we cannot ascertain whether departure from the wage-disadvantaged state is, itself, permanent or temporary.

It is also apparent from the Table 7 results that the probability of being in the wagedisadvantaged state varies according to the size of the location of employment. For example, compared to females working in very large firms, those working in smaller firms have a lower probability of being categorised as at a wage disadvantage in any given year, as well as a lower probability of remaining in a similar state in contiguous years. ${ }^{18}$ Moreover, females working in very large firms (i.e., 100 employees and over) have a slightly lower joint probability of being in different wage comparison categories in 1996 and 1997. For example, the predicted joint probability of being in the wagedisadvantaged category in 1996 and not being in this category in 1997 for women working in very large firms is 14 percent, compared to 15 percent for those working in medium sized and large firms. Furthermore, the conditional probability of exiting wage disadvantaged employment for females working in small (43 percent), medium (28 percent) and large (25 percent) firms is considerably larger than that for females working in very large firms (20 percent). This finding is consistent with large firms having well defined internal labour markets characterised by stable wage structures which offer

\footnotetext{
${ }^{18}$ Hellerstein, Neumark and Troske (1999) report that smaller firms are less able to indulge in sex discrimination in the U.S. because they have less market power.
} 
women relatively little opportunity for rapid change in economic status. It is also consistent with the market power argument of Hellerstein et al. (1999).

\section{SUMMARY AND CONCLUSION}

Studies of the Australian labour market during the 1980s reported that the male/female wage gap narrowed due to the equal pay decisions in 1969 and 1972 and the legislative reforms of the 1980s. However, more recent studies have shown that during the 1990s the gender pay gap has persisted. The main source of the gender pay gap is the differences in the treatment of males and females in the labour market. That is, for given sets of characteristics, females are paid at a lower rate than males. As these should represent the outcome of well established wage determination mechanisms, the gender pay gap is expected to be reasonably stable over time.

Consistent with previous studies, the average female worker's hourly wage in the SEUP data analysed is around 19 percentage points below that of males. Only a small part of the gender wage gap (16 percentage points in 1997) is attributable to differences in the mean observed characteristics of men and women. The large, unexplained, gender wage effect might imply a male treatment advantage or systematic treatment that disadvantages female workers [Cotton (1988)]. Consistent with this, there is a very high degree of stickiness in the wage distribution. Hence, a large number of females (90 percent) who were in the bottom 20 percent of the wage distribution in 1996 remain in the same state in 1997. However, there is also some upward and downward mobility within the wage distribution. The analysis shows that most of the movements within the wage distribution between 1996 and 1997 are due to stochastic variation in earnings rather than skill upgrading or changes in the other characteristics of females.

The results from single equation and bivariate probit models of the wage-disadvantaged state show that, on average, membership of the wage-disadvantaged category in any given year is 53 percent and in contiguous years is 38 percent. Membership of the wagedisadvantaged category is determined by educational attainment, English proficiency, marital status, disability, sector of employment and, importantly, the size of the location of employment. For example, the predicted joint probability of being at a wage disadvantage in both 1996 and 1997 for females who had left school at 15 years and under is 55 percent, compared to 41 percent for those who had completed high school and 
34 percent for those who have a bachelor degree or higher. For females working in very large firms the joint probability of being wage disadvantaged in 1996 and 1997 is 55 percent compared to 39 percent for those working in medium sized firms.

Overall, while some females escape from the wage-disadvantaged state over a 12-month period, there is also a relatively large number who remain in this state in contiguous years. Changes in female characteristics play a minor role in their departure from the wage-disadvantaged state.

These findings have several implications. First, it suggests that unlike youth, wage disadvantage may not be a temporary phenomenon among females. Hence, while previous studies have shown that the average female wage disadvantage has tended to persist over the past two decades, the results in this study tentatively suggest that the women disadvantaged are, by and large, likely to be the same group from year to year. ${ }^{19}$ Second, in determining membership of the wage-disadvantage category in a particular year, and of exit from that category, attention has been drawn to two wage determinants. The first of these is educational attainment, with the results showing a marked difference between the labour market success of those who left school before their $16^{\text {th }}$ birthday and the other educational attainments. Corrective action in this regard could focus on either the skills of these workers or the rates of remuneration of low-skilled females. The second wage determinant is size of location of employment, with the analyses reported in this paper drawing attention to the apparent key role played by large workplaces in both generating and perpetuating gender wage inequality in the Australian labour market. How the wage practices of large firms give rise to such an outcome can only be speculated on here. But previous Australian studies have drawn attention to the importance of intra-occupational wage effects as the key to understanding the gender pay gap in Australia. Large firms would be much more able than small firms to operate systems of classification consistent with large intra-occupational wage effects that disadvantage female workers. Comparable worth programs, focused on large firms, would be a consistent policy response.

\footnotetext{
${ }^{19}$ The limited time span covered by the data prevents strong conclusions being drawn.
} 
The findings reported in this paper add a new dimension to study of the gender wage effect in Australia. It is able to do this because of the longitudinal nature of the data collected in the SEUP database. This database is, however, limited by the fact that individuals were followed for only three years. A more powerful set of analyses could be conducted if longitudinal surveys covering a longer time span were available. This should be seen as a priority for individuals interested in this area of research. 


\section{APPENDIX A DEFINITIONS OF VARIABLES}

Hourly wage: This is a continuous variable and is computed from the usual weekly earnings of each job and the usual weekly hours worked in each job. For the usual weekly earnings of each job the mid-point of each band was used to construct a continuous measure of income. The open-ended upper limit was given a value 1.5 times the lower threshold level. Hourly earnings were derived by dividing the usual weekly earnings of each job by the usual weekly hours worked in each job. The dependent variable used in this paper is the natural logarithm of hourly earnings.

Wage disadvantage: This is a dichotomous variable and is set equal to unity if the individual receives a wage 10 percent or more below the predicted wage in 1996 or 1997. For individuals whose wage exceeds the threshold noted above the variable is set equal to zero.

Educational attainment: 7 categories of education are distinguished, with binary variables being created for (i) Bachelor degree or higher; (ii) Undergraduate or associate diploma; (iii) Skilled vocational qualification; (iv) Basic vocational qualification; (v) Attended highest level of secondary school; (vi) Left school at 16 years and over; and (vii) Left school aged 15 years and under.

Never worked: This is a dichotomous variable and is set equal to zero if the individual has worked prior to September $5^{\text {th }} 1994$. For individuals not meeting this criterion the variable is set equal to unity. This variable captures labour market entrant status.

Looking for work since first left full-time education: This is a continuous variable that measures the number of years the individual looked for work while not working since he/she left full-time education.

Duration of current job: This is a continuous variable that measures the number of years the individual has been employed in the current job.

Labour market experience: This is a continuous variable that measures the number of years in paid work since the individual first left full-time education.

Public sector: This is a dichotomous variable and is set equal to unity if the individual is employed in a public sector. Individuals not meeting this criterion are assigned a value of zero.

Size of location of employment: 4 categories of size of location of employment are distinguished, with binary variables being created for (i) 1-10 employees; (ii) 11-50 employees; (iii) 51-100 employees; and (iv) 100 employees or more.

English proficiency: 2 categories of English proficiency are distinguished, with binary variables being created for (i) Speaks English very well/well; and (ii) Speaks English fairly well/not well/not at all.

Marital status: 3 categories of marital status are distinguished, with binary variables being created for (i) Married; (ii) Separated/divorced/widowed; and (iii) Never married.

Birthplace: 3 categories of birthplace are distinguished, with binary variables being created for (i) Born in main English-speaking country; (ii) Born in other country; and (iii) Born in Australia. 
Female: This is a dichotomous variable and is set equal to unity if the individual is female. Males are assigned a value of zero.

Disability: This is a dichotomous variable and is set equal to unity if the individual has a disability. The variable is set equal to zero for individuals without a disability.

Period of residence: This is a continuous variable that measures the years foreign-born individuals have resided in Australia. It is computed from the year of arrival in Australia.

Geographical location: 4 categories of geographical location are distinguished, with binary variables being created for (i) Capital city; (ii) Major urban; (iii) Other urban; and (iv) Rural. 


\section{REFERENCES}

Australian Bureau of Statistics, (1997). Australia's Employment and Unemployment Patterns 1994-1996, Australian Government Publishing Service, Canberra.

Blinder, A.S., (1973), "Wage Discrimination: Reduced Form and Structural Estimates", Journal of Human Resources, Vol. 8 (4), pp.436-455.

Borland, J., (1999). "The Equal Pay Case-Thirty Years On", Australian Economic Review, Vol. 32 (3), pp.265-272.

Cotton, J., (1988). "On the Decomposition of Wage Differentials", Review of Economics and Statistics, Vol. 70 (2), pp.236-243.

Filer, R., (1993). "The Usefulness of Predicting Values for Prior Work Experience in Analysing Labor Market Outcomes for Women", Joumal of Human Resources, Vol. 28 (3), pp.519-537.

Fitzgerald, J., P. Gottschalk and R. Moffitt, (1998). "An Analysis of Sample Attrition in Panel Data: The Michigan Panel Study of Income Dynamics", Joumal of Human Resources, Vol. 33 (2), pp.251-299.

Frank, R.H., (1978). "Why Women Earn Less: The Theory and Estimation of Differential Overqualification", American Economic Review, Vol. 68 (3), pp.360-373.

Freebairn, J., M. Porter and C. Walsh, (1987). Spending and Taxing: Australian Reform Options, Allen \& Unwin, Sydney.

Heckman, J.J., (1979). "Sample Selection Bias as a Specification Error", Econometrica, Vol. 47 (1), pp.153-161.

Hellerstein, J.K., D. Neumark and K.R. Troske, (1999). "Wages, Productivity and Worker Characteristics: Evidence from Plant-Level Production Functions and Wage Equations", Journal of Labor Economics, Vol. 17 (3), pp.409-446.

Jones, E.B. and J.E. Long, (1979). "Part-week Work and Human Capital Investments by Married Women", Joumal of Human Resources, Vol. 14 (4), pp.563-578.

Kidd, P. and X. Meng, (1997). "Trends in the Australian Gender Wage Differential over the 1980s: Some Evidence on the Effectiveness of Legislative Reform", Australian Economic Review, Vol. 30 (1), pp.31-44.

Kidd, P. and M. Shannon, (1996). "The Gender Wage Gap: A Comparison of Australia and Canada", Industrial and Labor Relations Review, Vol. 49 (4), pp.729-746.

Kidd, P. and M. Shannon, (1997). "Imputation of Female Labour Market Experience: Some Australian Evidence on the Zabalza and Arrufat Method", Economic Record, Vol. 73 (221), pp.136-145. 
Kuhn, P., (1987). "Sex Discrimination in Labor Markets: The Role of Statistical Evidence", American Economic Review, Vol. 77 (4), pp.567-583.

Le, A.T. and P.W. Miller, (1998). "The ABS Survey of Employment and Unemployment Patterns", Australian Economic Review, Vol. 31 (3), pp.290-297.

Le, A.T. and P.W. Miller, (2000). "Poor Quality Jobs: Do They Lead to Churning?", in J. Mangan (Ed.), Understanding and Reducing Unemployment: National and State Perspectives, Office of Economic and Statistical Research, Treasury Department, (forthcoming).

Lillard, L.A. and R.J. Willis, (1978). "Dynamic Aspects of Earnings Mobility", Econometrica, Vol. 46 (5), pp.985-1012.

Meng, X., (1999). "Gender Earnings Gap: The Role of Firm Specific Effects", mimeo, The Australian National University.

Miller, P.W., (1989). "Low-wage Youth Employment: A Permanent or Transitory State?", Economic Record, Vol. 65 (189), pp.126-135.

Miller, P.W., (1994). "Effects on Earnings of the Removal of Direct Discrimination in Minimum Wage Rates: A Validation of the Blinder Decomposition", Labour Economics, Vol. 1, pp.347-363.

Preston, A.C., (1997). "Where Are We Now With Human Capital Theory in Australia?", Economic Record, Vol. 73 (220), pp.51-78.

Preston, A.C. and G.V. Crockett, (2000). "Equal Pay: Is the Pendulum Swinging Back?", Journal of Industrial Relations, Vol. 41 (4), pp.561-574.

Rummery, S., (1992). "The Contribution of Intermittent Labour Force Participation to the Gender Wage Differential", Economic Record, Vol. 68 (202), pp.351-364.

Stromback, T., M. Dockery and W. Ying, (1999). "Labour Market Programs and Labour Force Status", Australian Bulletin of Labour, Vol. 25 (2), pp.159-178.

Veall, M.R. and K.F. Zimmermann, (1996). "Pseudo-R ${ }^{2}$ Measures for Some Common Limited Dependent Variable Models", Joumal of Economic Surveys, Vol. 10 (3), pp.241-259.

White, H., (1980). “A Heteroscedasticity Consistent Covariance Matrix Estimator and a Direct Test of Heteroscedasticity", Econometrica, Vol. 48 (4), pp.817-818.

Wooden, M., (1999). "Gender Pay Equity and Comparable Worth in Australia: A Reassessment", Australian Economic Review, Vol. 32 (2), pp.157-171. 